\title{
The Impact of EFL Teachers' Assessment Literacy on Their Assessment Efficiency in Classroom
}

\author{
Mostafa Rahimi Rad \\ Allameh Tabatabai`e University, Tehran, Iran \\ Email : mostafa60rahimi@gmail.com
}

\begin{abstract}
:
Teachers in general and language teachers in particular are expected to assess various aspects of their teaching and learning. To achieve this, they are believed to familiar with different dimensions of assessment in general and classroom assessment in particular. Language teaching and assessment are two interrelated notions that affect each other to a great extent. Undoubtedly, language assessment is one of the most significant and complicated activities in the field of language teaching. The present study investigated assessment related perception and practices of Iranian EFL teachers. As assessment literacy questionnaire was distributed to 30 Iranian EFL teachers who were selected from two branches of private language institute, three teachers with high assessment literacy knowledge and three teachers with relatively low assessment literacy based on result of assessment literacy questionnaire were interviewed. The result of both qualitative and quantitative data indicated that EFL teachers' assessment literacy has meaningful and significant impact on Assessment efficiency in classroom. Teachers with high assessment literacy have a structured lesson plan and also know their learners`strengths and weaknesses clearly. This study suggest language policy makers to motivate language teachers to be assessment literate.
\end{abstract}

Keywords :

assessment literacy; teachers 'assessment literacy; assessment standards

\section{Introduction}

Teachers in general and language teachers in particular are expected to assess various aspects of their teaching and learning. To achieve this, they are believed to familiar with different dimensions of assessment in general and classroom in particular. This paper attempts to determine The Impact of EFL Teachers' Assessment literacy on their Assessment efficiency in classroom. Assessment literacy is multinational concept both in term of decision making realities. Assessment literate person can describe the achievement targets in any specific context in specific terms. They can describe the knowledge to be learned. The sort of assessment literacy that is typically recommended to teacher`s familiarity with those measurement basics related directly to what goes on in classroom. We need to stop of assessment merely as an accountability tool and start using it as teaching tool.

Assessment is definitely one of the most significant and complicated tasks. Many educational systems are attempting to upgrade their testing procedures to incorporate new approaches and techniques. Therefore, teachers ` knowledge of assessment or assessment literacy has a great effect on the quality of education. That is why the notion of assessment literacy has inaugurated a new line of research in literature on assessment. For example, Fery and Schmitt (2007) identified six purposes for assessment: 1. Screening and identification, 2. Placement, 3. Reclassification or exit, 4. Monitoring students' progress, 5. Program evaluation and 6. Accountability.

The best definition of assessment literacy is from Webb (2002) who defines it as "The knowledge about how to assess what students know and can do, interpret the results of those 
assessments, and apply the results to improve student learning and program effectiveness". Hence, 'assessment literate' educators should possess a number of skills connected with the fundamental issues of profound assessment practices. These skills include: defining learning objectives that can be assessed, making use of the different available assessment methods, making inferences from analyzing students' work, providing constructive feedback to students and communicating the results of assessment effectively (Sadler, 1998).

It can be stated that despite the important role of classroom assessments in influencing their teaching and their students' learning, teachers generally leave assessment issues to be considered at a later time of the academic year. This suggests the prominent use of assessment to measure students' achievements - assessment of learning- rather than assessment to help students learn - assessment for learning.

Assessment of student is one of the most important responsibilities of teachers, because the quality of teaching in classroom is closely associated with the quality of the applied assessment. Hence it is essential for teachers to possess assessment literacy. Assessment literacy is important because it helps teachers to perceive, analyze and use data on student performance to improve teaching. Stakeholders are influenced by language tests, therefore; being assessment literate is more vital for them, because assessment illiteracy results in inaccurate assessment and consequently the purposes of assessment could not be fulfilled. It is necessary for teachers to develop language assessment literacy to prevent serious consequences for teachers and students. Assessment is a vital element in the overall quality of teaching and learning in schools. The most effective way of enhancing learning is to have teachers who really know how to use assessment as a teaching tool to promote learning. Assessment literacy, as a term, is not well known in the educational field. This is unfortunate because teachers' assessment knowledge and competence can have an important influence on the way they teach and the way their students learn.

\section{Review of Literature}

Language assessment refers to "the act of collecting information and making judgments on a language learner's understanding of a language and his ability to use it" (Chapelle \& Brindley, 2002, p. 267). It is, thus, an interpretation of the test taker's ability to use some aspects of this language (Bachman \& Palmer, 2010). It is worth noting that being able to use a language entails interacting with others, in a given setting, to create or interpret intended meanings within a particular discourse (Bachman \& Palmer, 2010). Though assessment is undertaken for a variety of purposes (e.g. formative or summative assessment), the primary purpose remains to support learning which occurs when learners are, according to Cameron, Tate, Macnaughton and Politano (1998):

Thinking, problem-solving, constructing, transforming, investigating, creating, analyzing, making choices, organizing, deciding, explaining, talking and communicating, sharing, representing, predicting, interpreting, assessing, reflecting, taking responsibility, exploring, asking, answering, recording, gaining new knowledge, and applying that knowledge to new situations (p. 6).

Improving assessment practice remains the concern of several researchers who are attempting to find out how to make this process support learning. To do so, there has been a need to account for what constitutes good or "sound" language assessment, whose characteristics, as put forward by Stiggins (2007, cited in Coombe et al., 2009, p. 16), are:

- They arise from and serve clear purposes.

- They arise from and reflect clear and appropriate achievement targets. 
- They rely on a proper assessment method (given the purpose and the target).

- They sample student achievement appropriately.

- They control for all relevant sources of bias and distortion.

So, in summary, effective or sound assessment is purposive and targets clear and relevant objectives which can contribute to both evaluating and developing learners' language ability. Moreover, it uses appropriate assessment methods according to the set objectives and communicates assessment results to all stakeholders who are involved in the process. Sound assessment also needs to develop valid and reliable grading by maintaining control over the variables that may distort its results. In addition to reliability and validity, Bachman and Palmer (1996, cited in Daalen, 1999) add other terms which refer to test usefulness such as authenticity, interactiveness, practicality and impact.

\section{LAL may be defined as:}

The knowledge, skills and abilities required to design, develop, maintain or evaluate large-scale standardized and/or classroom based tests, familiarity with test processes, and awareness of principles and concepts that guide and underpin practice, including ethics and codes of practice. The ability to place knowledge, skills, processes, principles and concepts within wider historical, social, political and philosophical frameworks in order understand why practices have arisen as they have, and to evaluate the role and impact of testing on society, institutions, and individuals (Fulcher, 2012, p. 125).

Melone (2013) put instructional issues at the core and defined LAL as "language instructors' familiarity with testing definitions and the application of this knowledge to classroom practices in general and specifically to issues related to assessing language" (p. 329). On the other hand, Scarino (2013) emphasized the central role of teachers in assessment; therefore, LAL has also been defined as "the assessment of student achievements, teacher knowledge, understanding and practices of assessment" (p. 310). Finally, LAL may be regarded as a repertoire of competences used for understanding, evaluating and creating language tests and analyzing test data (Phill \& Harding, 2013).

It is true that teachers are at the heart of every educational process in the classroom. Success of any educational reform depends on the teachers', as the implementers of the system, understanding and application of the requirements of the reform. Thus, as attempts have been made to bring about necessary changes and improvements in teaching, learning, and assessment in schools, it is important to explore

The knowledge base in the case of language assessment makes reference to the body of theoretical and practical knowledge that language teachers including EFL teachers require in relation to aspects such as the purpose of assessment, the appropriateness of the assessment tools being used, the testing conditions, the interpretation and implications of results, etc.

Other authors (Popham, 2009; Schafer, 1993; Stiggins, 1999) have also attempted to define what constitutes the knowledge base of assessment for teachers across various areas including EFL education. Stiggins (1999) suggested a list of seven content requirements or competences aimed to provide a comprehensive foundation in assessment practices. These included (a) connecting assessments to clear purposes, (b) clarifying achievement expectations, (c) applying proper assessment methods, (d) developing quality assessment exercises and scoring criteria and sampling appropriately, (e) avoiding bias in assessment, ( $\mathrm{f}$ ) communicating effectively about student achievement, and $(\mathrm{g})$ using assessment as an instructional intervention. Training within these seven competencies will undoubtedly bring significant benefits not only to our EFL teachers, in the sense 
that they will have a clearer picture of what students may know (declarative knowledge) and what they can do (procedural knowledge), but also to their EFL students in the sense that they may be provided with more reliable assessment instruments, practices, and conditions.

Accordingly, teachers need to be skilled in aspects such as choosing and developing appropriate assessment methods for instructional decisions; administering, scoring, and interpreting assessment results to make decisions for planning and improving teaching; developing valid grading procedures; communicating results to students, parents, and others; and recognizing unethical or inappropriate methods and uses of assessment. These standards, constructed by the American Federation of Teachers, the National Council on Measurement in Education, and the National Education Association (1990), embrace the concept that assessment and instruction are reciprocally linked and that effective instruction cannot occur without good assessment of learning.

\section{Methodology}

The purpose of the current study was to investigate teacher`s knowledge of assessment and its reflection and efficiency in their classroom. This study is descriptive in which both quantitative and qualitative methods of language teaching were used. The present study investigated assessment -related perceptions and practices of Iranian EFL teachers. A reliable assessment literacy questionnaire distributed to 30 Iranian teachers. Then, six EFL teachers (three teaches with high assessment literacy and three with low or no assessment literacy were selected based on the results of assessment literacy questionnaire.

This study is a reliable assessment literacy questionnaire distributed to 30 Iranian EFL instructors. Descriptive in which Quantitive and qualitative methods of language testing is used. The present study investigated assessment-related perceptions and practices of Iranian EFL teachers. Then six EFL teachers (three teachers with high assessment literacy and three teachers with low or no assessment literacy are selected based on the result of assessment literacy questionnaire.). The present study investigated assessment -related perception and practices of Iranian EFL teachers were selected non - randomly from available language institutes.

From 30 participants three teaches with high assessment literacy and three teaches with low or no assessment literacy were selected for interview. The age of participants ranged from 2840. They had 5 to 15 years of teaching experiences. They taught English in different English Language institutes in Tehran.

The researcher employed different instruments to enhance the quality of data. A description of instruments that were employed in the current study appears follow:

Assessment literacy questionnaire a modified version of Howell (2013), this scale addresses issues in applying assessment practices in the classroom. Each item is followed by a scale ranging from 1 (very low) to 5 (very high). Assessment literacy questionnaire was based on the Teacher Assessment Literacy questionnaire. This questionnaire consists of 36 items related to a classroom teacher. Some of the items measure general concepts related to testing and assessment, including the use of assessment activities for assigning student grads and communicating the results of assessment to students and parents; other items related to knowledge of standardized testing.

A modified version of Howell (2013) assessment literacy questionnaire was based on the Teacher Assessment Literacy questionnaire. This questionnaire consist of 36 items. Some of items 
which are related to the participants` background as a classroom teacher and some items related to the standard for teachers competence in Educational Assessment of students. (See Appendix A) Some of items measure general concepts related to testing and assessment, including the use of assessment activities for assigning student grades and communicating the results of assessment to students and parents, other items are related to knowledge of standardized testing. The researcher conducted a semi - structured interview with six instructors to examine their assessment literacy. In this face to face interview that was conducted in 30 minutes, the interviews were asked to talk about language assessment related topics. The topics were about: general concepts related to testing and assessment, knowledge of standardized testing.

The observation process is a three-stage funnel, beginning with descriptive observation. In this study, the researcher employed non-participants observation. Non- participant observation involves observing participants without activity participating. This option is used to understand a phenomenon by entering the community or social system involved, while staying separate from the activities being observed.The researcher chose 30 teachers from two language institute in Tehran. Then, he administered the assessment literacy questionnaire. Based on result of this questionnaire, he chose three teachers with high assessment literacy and three teachers with low or no assessment literacy as the participants of the study. They taught English in their institutes. He employed classroom observation (non -participation observation) and semi - structured interview to determine their difference in their perception as well as their classrooms 'practices. To investigate the effect of assessment literacy on students 'outcomes. It should be mentioned that for completing questionnaire the teachers were given enough time. Data was collected between March and May 2019. Then all questionnaires were analyzed for the purpose of data analysis. The sampling method was convenient available method. The Qualitative data included all open -ended responses to the interviews and classroom observation. The procedure for analyzing qualitative data was as follow: Each data set was read several times to gain some sense of the main ideas being expressed. Then data was coded and analyzed manually and subjectively. The quantitative data for current study was The instrument include the Classroom Assessment Literacy Inventory ( Howell, 2013) which was adapted from a similar instrument called the Teacher Assessment Literacy Questionnaire, This questionnaire consist of 36 items, the items were aligned with "Standards for Teacher Competence in the Educational Assessment of Students" (AFT, NCME, \& NEA, 1990). This questionnaire utilized to understand teacher's knowledge and basic elements and principles in educational assessment.

\section{Discussion}

The qualitative and quantitative data are the result of interview and classroom observation. At the outset the study, to choose the main participants of study (teachers with and without assessment literacy), the researcher distributed the assessment literacy questionnaire to 30 EFL teachers. As the number of teachers is low, the results of questionnaire are analyzed manually by (SPSS) version 18. The researcher ranked the results of the TALQ and choose three teachers the highest ranks and three teachers with lowest rank. The TALQ consists of 36 questions. One score is assigned to each question. The scores of teachers in high rank are 20,19, and 18(teachers with assessment literacy), and the scores in low rank are 8, 9, and 10 (teachers with less assessment literacy than high rank). The six teachers are chosen for the current study.

After collecting the necessary data, the researcher used the descriptive statistics to interpret the data, this study attempts to investigate the assessment literacy of EFL teachers. For this purpose one questionnaire was administered and the data was collected. 
The questionnaire was based on seven standards related to assessment literacy of teachers, they are included

1. Teachers should be skilled in choosing assessment methods appropriate for instructional decisions.

2. Teachers should be skilled in developing assessment methods appropriate for instructional decisions.

3. Teachers should be skilled in administering, scoring, and interpreting the results of both externally-produced and teacher-produced assessment methods.

4. Teachers should be skilled in using assessment results when making decisions about individual students, planning teaching, developing curriculum, and school improvement.

5. Teachers should be skilled in developing valid pupil grading procedures which use pupil assessments.

6. Teachers should be skilled in communicating assessment results to students, parents, other lay audiences, and other educators.

7. Teachers should be skilled in recognizing unethical, illegal, and otherwise inappropriate assessment methods and uses of assessment information.

Table 1. Teachers' Assessment Literacy

\begin{tabular}{|l|c|c|c|c|}
\hline Groups & N & Mean & SD & T-value \\
\hline High literacy & 3 & 18.39 & 1.317 & 3.291 \\
& & & & \\
\hline Low literacy & 3 & 10.96 & 1.461 & \\
& & & & \\
& & & & \\
\end{tabular}

The results of the study showed that the mean and standard deviation of scores are (18.39, $\mathrm{SD}=1.317)$ for high literacy group and $(\mathrm{M}=1096, \mathrm{SD}=1.461)$ for low literacy group

This study reported that teachers are insufficient in alternative and performance assessment methods. The needs of teachers should be identified, some teachers are not enough knowledgeable in which how to assess students. The educational system can provide programs in the area of assessment. Also providing workshops based on standards for teacher competence in educational assessment of students. Teachers often seem unable to affect the policy and resist external imposition. It is suggested that language teachers engaged in classroom assessment practices and familiarized with these standards in order to do profession of assessment. Focus on teachers' understandings of Standards and criteria were also emphasized by Fulcher, (2012) in the area of assessment for learning.

Assessment is the bridge that links the curriculum and the instruction, it reflects many goals (Oleksak, 2007), there are so many changes in the form of assessment, teachers in the area of assessment should be competent enough, it is better they familiar with different competencies including selecting assessments, developing assessments for the classroom, administering and scoring tests, using scores to aid instructional decisions, communicating results to stakeholders, and being aware of inappropriate and unethical uses of tests. Teachers need to be more competent in the rigors of assessing student learning to determine how effective their instruction are in 
developing student targets. The development of assessment competencies depends on the kind of experience and training that teachers receive in their pre-service years (Cizek, Fitzgerald, \& Rachor, 1996).

Teachers should be offered long-term and comprehensive in-service training programs on alternative and performance assessment methods. Training programs for teachers should be also based on practice more and find solutions for problems of teachers that may face. They should be provided appropriate materials and resources about novel alternative assessment methods (Birgin \& Baki, 2009).

The participants of this study consisted of 30 instructors enjoying various educational status and levels of experience from different English language institutes in Iran, selected by convenience sampling. Their teaching experiences ranged from 5 to 15 years. Of these participants, 3 had Bachelor's degrees; 13 were reading for a Master's degree in Teaching English as a Foreign Language (TEFL); 14 were reading for a doctorate degree in TEFL. Participants were divided into three groups based on their teaching experience (low, mid, high). The following table shows the features of the participants of this study.

Table 2. The relationship between EFL teachers' assessment literacy and years of experience

\begin{tabular}{|c|c|c|c|}
\hline $\begin{array}{c}\text { Teaching } \\
\text { experience (years) }\end{array}$ & $5-11$ (low) & $11-15$ (high) & $6-10$ (mid) \\
\hline $\begin{array}{c}\text { Number of } \\
\text { participants }\end{array}$ & $13(33.3 \%)$ & $3(50 \%)$ & $14(16.7 \%)$ \\
\hline
\end{tabular}

As is evident from Table 2, there is a statistically significant positive correlation between assessment literacy and years of experience. That is to say the higher the years of experience the more literate the teachers will be.

The Qualitative Data of the present study are the teachers' answers to interview questions and classroom observation.

A semi - structured interview is conducted with six instructors to elicit in -depth information about their assessment literacy. In this face -to face interview that was conducted in almost 30 minutes. The interviewees were free to talk about other issues related to assessment in general and assessment in particular. The steps in the interview were as follow: general concepts related to testing and assessment, the use of assessment activities for assigning student grades, communicating the results of assessment to students and parents, knowledge of standardized testing, and classroom assessment.

The main concerns in the HL group interviews were as follow:

(1) "Classroom is a kind of testing strategy."

(2) "Testing and teaching are so closely interrelated that it is impossible to work in the classroom without them"

(3) "Assessment is the best way that teachers can evaluate their students' unintentionally"

(4) "Effective teaching is somehow impossible without considering assessment in the classroom"

(5) "It is just through assessment that learners can understand their strength and weakness so they can improve their performance in the classroom"

(6) "Teachers using assessment and its related techniques to meet students ' needs and most importantly to achieve a greater equity of reaching should be the main part of every class." 
On the basis of what the HL teacher said, it can be inferred that they try to integrate assessment and teaching. Moreover, assessment is considered as a teaching strategy that can help teachers to recognize the needs of language learners.

The main concerns in LL group interviews were as follow:

(1) "We cannot do anything when we have fixed educational system with standardized tests. Teachers cannot focus on their skills freely."

(2) "The name of the assessment or test has stressful feeling for both teachers and students. Students ordinary actions will change if they understand they are evaluated internally or unintentionally."

(3) "We do not have enough time to think about classroom assessment."

(4) "When teachers have a set of standardized test, it is hard to them to think about ongoing assessment."

(5) "Assessment requires more energy and time; some teachers are demotivated to do because of financial matters."

The observation process is a three- stage funnel, begging with descriptive observation, in which researchers carry out broad scope observation to get an overview of the setting, moving to focused observation, in which they start to pay attention to narrower portion of the activities that most interest them, and then selected observation, in which they investigate relations among the elements they have selected as being of greatest interest. Observation should end when theorical saturation is reached, which occurs when further observation begin to add little or nothing to researchers ' understanding. In this study, the researcher employed non-participant observation. Non-observation involves observing participants without actively participating. This option is used to understand a phenomenon by entering the community or social system involved, while staying separate from the activities being observed.

In the HL group, teachers asked some questions after any points in their classroom to check their learners 'understanding. They followed their teaching with quiz to sure that their students get the points. In these classroom, students can choose what to learn and what not to learn to some extent; it means that teachers respected the students`needs and interests.

\section{Conclusion}

In LL group, teachers followed the material exactly as what it was. They just followed the teaching methods were designed by experts in the field. They repeated every new point, but they did not check students' understanding. They did not take and just say: "read parts carefully, these points are so important and will be apart of your final exam. The results of observation therefore, showed that there is a significant difference between the classroom practices of teachers with assessment literacy and teachers with low assessment literacy.

In sum, the results of both quantitative and qualitative data indicated that EFL teachers assessment literacy has meaningful and significant impacts on their classroom practices and their learners' understanding. Teachers with high assessment literacy have a structured lesson plan and also know their learners strengths and weaknesses. 


\section{References}

Alkharusi, H. (2011). Psychometric properties of the teacher assessment literacy questionnaire for preservice teachers in Oman. International conference on Education and educational psychology, 29 (2011) 1614, 1624.

Brindley, G. (2001). Outcomes-based assessment in practice: Some examples and emerging insights. Language Testing, 18(4), 393-408.

Campbell, C., Murphy, J. A., \& Holt, J. K. (2002). Psychometric analysis of an assessment literacy instrument: Applicability to pre-service teachers. Paper presented at the annual meeting of the Mid-Western Educational Research Association, Columbus, $\mathrm{OH}$.

Davies, A. (2008). Textbook trends in teaching language testing. Language Testing, 25(3), 327-347.

Fulcher, G. (2012). Assessment literacy for the language classroom. Language Assessment Quarterly, 9(2), 113-132. DOI: 10.1080/15434303.2011.64204.

Mertler, C. A. (2003). Preservice versus inservice teachers' assessment literacy: Does classroom experience make a difference?. Paper presented at the annual meeting of the Mid-Western Educational Research Association, Columbus, OH, October. Retrieved from http://wps.ablongman.com/wps/media/objects/1530/1567095/ tchassesslit.

Mertler, C. A. (n.d). Classroom Assessment Literacy Inventory. Retrieved from http://pareonline.net/htm/v8n22/cali.htm.

Schafer, W. D. (1991). Essential assessment skills in professional education of teachers. Educational Measurement: Issues and Practice, 10(1), 3-6.

Schafer, W. D., \& Lissitz, R. W. (1987). Measurement training for school personnel: Recommendations and reality. Journal of Teacher Education, 38(3), 57-63.

Popham, W. J. (2009). Assessment Literacy for Teachers: Faddish or Fundamental?. Theory Into Practice, (48), 4-11. https:// doi.org/10.1080/00405840802577536

Stiggins, R. J. (1995). Assessment literacy for the 21 st century. Phi Delta Kappan,77(3), 238-245.

Stiggins, R. J. (2002). Assessment crisis: The absence OF assessment FOR learning. Pbi Delta Kappan, 83, 758765.

Taylor, L. (2009). Developing assessment literacy. Annual Review of Applied Linguistics, 29, 21-26.

Tomlinson, B. (2003). Developing materials to develop yourself. Humanising language teaching. Retrieved from http://www.hltmag.co.uk/jul03/mart1.htm.

Yamtim, V. \& Wonwanich S. (2013) A study of classroom assessment literacy of primary school teachers, 5 th World Conference on Educational Sciences - WCES 